\title{
Malaria and Lymphatic Filariasis Co-Transmission in Endemic Health Districts in Burkina Faso
}

\author{
Sanata Coulibaly¹, Simon Péguédwindé Sawadogo', Aristide Sawdetuo Hien1, \\ Achille Sindimbasba Nikièma ${ }^{1}$, Ibrahim Sangaré ${ }^{2}$, Bamogo Rabila1, Lassane Koala1, \\ Clarisse Bougouma ${ }^{3}$, Roland Windtaré Bougma ${ }^{3}$, Georges Anicet Ouedraogo², \\ Roch Kounbobr Dabiré ${ }^{*}$
}

\begin{abstract}
${ }^{1}$ Institut de Recherche en Sciences de la Santé/Direction Régionale de l'Ouest, Bobo-Dioulasso, Burkina Faso
${ }^{2}$ Université Nazi Boni, Bobo-Dioulasso, Burkina Faso

${ }^{3}$ Programme National de lutte Contre les Maladies Tropicales Négligées, Ministère de la Santé, Ouagadougou, Burkina Faso

Email: sanata15coulibaly@gmail.com, sawsimp2005@yahoo.fr, aristide.hien@yahoo.fr, achille.nikiema@yahoo.fr, babaibrasangare@yahoo.fr, rabilabamogo@yahoo.fr, koalalassane@gmail.com, obclarisse@hotmail.com, rolandbougma@yahoo.fr,ogeorgesanicet@yahoo.fr, ‘dabireroch@gmail.com
\end{abstract}

How to cite this paper: Coulibaly, S., Sawadogo, S.P., Hien, A.S., Nikièma, A.S., Sangaré, I., Rabila, B., Koala, L., Bougouma, C., Bougma, R.W., Ouedraogo, G.A. and Dabiré, R.K. (2021) Malaria and Lymphatic Filariasis Co-Transmission in Endemic Health Districts in Burkina Faso. Advances in Entomology, 9, 155-175.

https://doi.org/10.4236/ae.2021.94014

Received: June 15, 2021

Accepted: October 12, 2021

Published: October 15, 2021

Copyright $\odot 2021$ by author(s) and Scientific Research Publishing Inc. This work is licensed under the Creative Commons Attribution International License (CC BY 4.0).

http://creativecommons.org/licenses/by/4.0/ (c) (i) Open Access

\begin{abstract}
Introduction: Lymphatic filariasis (LF) and malaria are two vector-borne diseases which parasites can simultaneously infect human or mosquito. In Burkina Faso, studies mainly focused on the control of these diseases independently. Hence, there is a lack of information on their co-transmission of to both human and vector. The present study aimed at providing baseline data from endemic areas in Burkina Faso towards a successful integrated management of both diseases. Methods: The study was carried out in six sites distributed in the East, Center-East and South-West regions of Burkina Faso. Data were collected in August 2014 and September 2015. The infection rates in human and vector populations, vector diversity, trophic and resting behavior were investigated. To determine the disease prevalence nocturnal fingerprick blood sample and microscopic observations were performed. Vectors collected by human landing catches and pyrethrum spray collections. Biochemical and molecular analyses were performed to identify Anopheles gambiae sensu lato sibling species, and to determine vector infection rate and their blood meal origins. Results: Results indicate residual transmission of LF and malaria in human and vector populations. A low co-infection rate $(<1 \%)$ with Wuchereria bancrofti and Plasmodium falciparum was noted in both human and mosquito. Anopheles gambiae s.l., An. funestus s.l. and An. nili were by order the main potential vectors encountered. It was in majority parous females and exhibited endophagic and exophagic behavior. Parasite's co-infec-
\end{abstract}


tion was found with An. coluzzii and An. nili only. Conclusion: The present study has provided basic information on the (co-)transmission of both diseases in the study areas. These results will be useful for further investigations towards the development and implementation of a better integrated strategy to control these diseases.

\section{Keywords}

Wuchereria bancrofti, Plasmodium falciparum, Mosquitoes, Co-Infection

\section{Background}

Vector borne diseases, lymphatic filariasis (LF) and malaria, constitute high burdens of public health. Indeed, according to the World Health Organization (WHO), 228 million of morbidity and 405,000 deaths due to malaria were estimated in 2018 [1]. In addition, 51 million people are suffered from LF worldwide in 2017 [2]. Malaria and LF are transmitted by the same mosquito species and then can be co-transmitted to both mosquito and human in West Africa [3]. In this part of continent, the parasites responsible for malaria and LF are mainly Plasmodium falciparum and Wuchereria bancrofti [4] respectively and their major vectors are Anopheles gambiae s.l. and An. funestus s.l. [3] [4] [5] [6]. Significant advances in the monitoring, control, and elimination of LF and malaria have been recorded along years [7] [8]. In Burkina Faso, the control of LF using Mass Drug Administration (MDA) with ivermectin + albendazol is ongoing since almost two decades. At the time of the current study, most endemic communities would have stopped transmission and started transmission assessment survey (TAS) or post-MDA surveillance [9]. However, in some health districts particularly in the Center-East, East and South-West regions of the country the prevalence of microfilariae is still above 1\%, which is far from the elimination level [9] [10]. To fight against malaria, a national control program is undertaken since 1991. The aim of this program is to reduce morbidity and mortality related to malaria by cases management, chemoprevention and vector control. Currently, the country has made significant efforts in preventing malaria by vector control through longlasting insecticidal nets (LLINs) and indoor residual spraying (IRS) of insecticides [11] [12]. Despite these efforts, malaria remains endemic and is responsible of many cases of morbidity and mortality in the country [13].

Parasites of LF and malaria are transmitted mainly by An. gambiae s.l. and An. funestus s.l. in the country [5]. According to the WHO Office for Africa, integrated vector management is the best approach to improve the efficacy, costeffectiveness, ecological soundness, and sustainability of both diseases control [14] [15]. Indeed, in areas where malaria and LF are transmitted by the same vectors, interventions against malaria such as the use of LLINs and indoor residual sprays had significant impact, which may has been even greater against LF than malaria [16] [17] [18]. However, the change in mosquito biting and resting 
behavior [19] [20], in addition to insecticide resistance [21] [22] could jeopardize the success of vector control operations. Therefore, to set up towards the designation and implementation of an integrated, simultaneous attack against LF and malaria would be to understand both parasites transmission. Moreover, although number of studies that have investigated the impact of LLINs on malaria [23] and that of MDA on LF [9] [10], little information is available on the cotransmission of these diseases to both human and vector populations. To develop an effective integrated management strategy of these diseases, it is important to know their co-transmission patterns. The present study has investigated the vector behavior and the co-transmission of $W$. bancrofti and $P$. falciparum to both mosquito and human populations in areas of Burkina Faso where malaria is endemic and LF transmission persist.

\section{Methods}

\section{Study sites}

The study was carried out in six sites, distributed in Fada, Koupéla, Ouargaye and Diébougou health districts (Figure 1). These sites were selected on the basis of prevalence data of LF and malaria from surveillance activities carried out by the National Neglected Tropical Disease Control Program (NNTDCP), National Malaria Control Program (NMCP) and previous studies [9] [10] (Table 1). The study sites are: Seiga, Koulpissy (in Fada); Renghin (in Koupéla); Tangonko, Tensobtenga (in Ouargaye) and Saptan (in Diébougou). The number of inhabitants of each village in 2016 was in Koulpissy 1747; Seiga 1425; Tangonko 505; Tensobtenga 1627; Renghin (Baskouré) 479 and Saptan 346.

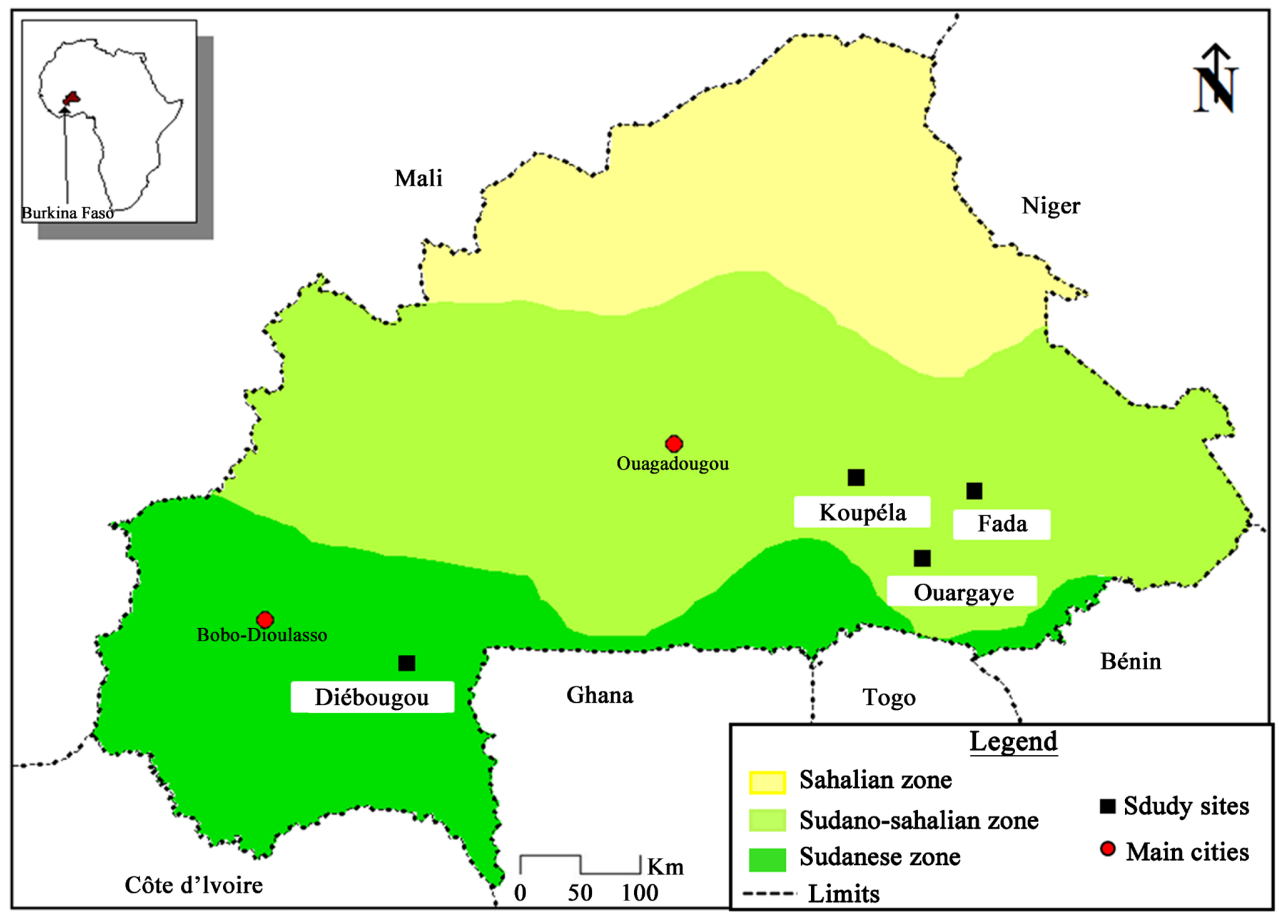

Figure 1. Map of Burkina Faso showing the locations of study sites. 
Table 1. Prevalence of $W$. bancrofti and $P$. falciparum infection, number of mass drug administration (MDA) rounds, therapeutic coverage rate and LLINs coverage rate in the study sites.

\begin{tabular}{cccccc}
\hline \multirow{2}{*}{ Site } & \multicolumn{5}{c}{ Year 2014 } \\
\cline { 2 - 6 } & $\begin{array}{c}\text { Prevalence of } \\
\text { Wb infection (\%) }\end{array}$ & $\begin{array}{c}\text { Prevalence of Pf } \\
\text { infection (\%) }\end{array}$ & $\begin{array}{c}\text { Nb rounds } \\
\text { of MD }\end{array}$ & $\begin{array}{c}\text { Coverage rate for } \\
\text { LF treatment }\end{array}$ & $\begin{array}{c}\text { Coverage rate } \\
\text { for LLINs (\%) }\end{array}$ \\
\hline Seiga & 1.7 & 89.4 & 12 & 79.6 & 77.9 \\
Koulpissy & 3.2 & 89.4 & 12 & 79.6 & 77.9 \\
Renghin & 0 & 81.8 & 12 & 80.3 & 96 \\
Tangonko & 0.59 & 89.8 & 12 & 81.4 & 96 \\
Tensobtenga & 1.08 & 89.8 & 12 & 81.4 & 96 \\
Saptan & 3.9 & 90.4 & 17 & 83.8 & 84.4 \\
\hline \multirow{2}{*}{ Seiga } & 3.27 & 86.3 & 13 & 86.3 & - \\
Koulpissy & 3.27 & 86.3 & 13 & 86.3 & - \\
Renghin & 0 & 82.4 & 13 & 82.4 & - \\
Tangonko & 3.48 & 84.3 & 13 & 84.3 & - \\
Tensobtenga & 3.48 & 84.3 & 13 & 84.3 & - \\
Saptan & 6 & 94.7 & 19 & 94.7 & - \\
\hline
\end{tabular}

Wb: Wuchereria bancrofti; Pf: Plasmodium falciparum; Nb: Number; LF: Lymphatic filariasis; LLINs: Long Lasting Insecticidal Nets.

The health districts of Fada, Koupéla and Ouargaye are in the Sudano-sahelian zone with two seasons, a dry season, and a rainy season. The dry season extends from November to April. The rainy season extends from May to October with an annual rainfall of 600 to $800 \mathrm{~mm}$ and the maximum peak in August-September. This zone is characterized by water systems sparse and savannah vegetation type. Diébougou health district is in the Sudanese zone, with an annual rainfall of 1000 to $1200 \mathrm{~mm}$ which extends from May to October. The dry season extends from November to Mars. This zone is characterized by a dense hydrographic network and wooded type savannah vegetation dotted with clear forest and gallery.

\section{Nightly thick blood smears collections for parasitological analysis}

The parasitological samples were collected in August 2014 and September 2015 from individuals of between 05 and 65 years of age. Collections were performed in all the sites between $12 \mathrm{pm}$ to 02 am on two day every month. Parents' consent was obtained before any blood collection from their children. Three drops of blood corresponding to $20 \mu \mathrm{l}$ each or about $60 \mu \mathrm{l}$ were collected into a clean glass object. The thick blood films were air-dried for one night at room temperature and were fixed in ethanol, then stained the next day with $10 \%$ Giemsa (Sigma) in phosphate buffer ( $\mathrm{pH}$ 7.0) for 30 minutes. Afterwards, they were soaked, rinsed, dried, and then wrapped with toilet paper and transported to the laboratory. Every slide was examined by two independent readers under microscope at x100 magnification to determine for the presence or not of micro- 
filariae and trophozoites. The species of microfilariae and trophozoites were identified. All the positive cases were notified to the health center for treatment as recommended by NNTDCP and NMCP.

\section{Mosquito collections}

Mosquitoes were collected in August 2014 and September 2015 by two sampling methods, the human landing catch (HLC) and the Pyrethrum Spray Catch (PSC). Human landing catches (HLC) was used to estimate the human biting rates. In each village, five houses were randomly chosen and they were distributed approximately $100 \mathrm{~m}$ apart. In such a way to have a representative geographical distribution and during two consecutive nights in both periods. In a house assigned to HLC, two local volunteers, one indoors and the other outdoors, collected mosquitoes landing on exposed legs and feet from 20:00 to 06:00. Collectors (all adult males) were regularly rotated to reduce collector-mediated bias in the results and supervision was provided to ensure collectors stayed awake thus reducing any potential for biting. The mosquitoes collected in each house were stored by collection origin (indoor and outdoor) and in hourly tranches. To estimate mosquito abundance in each village, indoor resting mosquitoes were collected in the both period by PSC between 06 am to $09 \mathrm{am}$. In each site a total of 10 houses were randomly selected per collection period. The collected mosquitoes were morphologically identified according to the morphological identification key describe by Gillies and Coetzee [24]. The repletion status of An. gambiae s.l. and An. funestus s.l. females collected from the PSC was recorded. All vectors collected and analyzed in the field were kept in Eppendorf tubes containing silica gel for further analysis in the laboratory.

\section{Determination of age gradient of mosquitoes}

To estimate vectors parity rate in each site, the ovaries of 150 females from Anopheles genus caught by HLC indoors and outdoors methods and random selected were monthly dissected. The parity rate was determined by observing the coiling of ovarian tracheoles [25]. Examination of dissected ovaries allowed to separate parous females (which had already laid eggs at least once) of nulliparous females (which had not yet laid eggs).

\section{Mosquito blood meal source detection}

Blood-fed females of Anopheles genus from PSC were used to determine host preference for blood meal intake. A random selection of 50 specimens per site and per period were analyzed by a direct enzyme-linked immune-sorbent assay (ELISA) [26] using anti-host (IgG) conjugated against human, bovine, pig, goat or sheep and donkey blood. Vector anthropophilic rate was calculated as the proportion of mosquitoes fed on human based on the total number of analyzed females.

\section{Species composition}

A sub-sample of 360 unfed females of An. gambiae s.l. were processed by Polymerase Chain Reaction (PCR) for molecular identification at the species level by using legs and wings. Their heads and thoraces were used to determine the 
infection status. Genomic DNA of mosquitoes was extracted with $2 \%$ cetyl trimethyl ammonium bromide (2\% CTAB). Then, Sine 200X 6.1 locus protocols described by Santolamazza et al., [27] were used to identify the members of $A n$. gambiae complex.

Detection of Plasmodium falciparum and Wuchereria bancrofti infections in the vectors

For W. bancrofti and P. falciparum detection, only An. gambiae s.l., An. funestus s.l. and An. nili species heads and thoraces were tested. Two PCR methods were used to determine the vectors infection with both parasites: the conventional PCR and the Loop-mediated isothermal amplification PCR (LAMP), using DNA from heads and thoraces of mosquitoes grouped by pool. The conventional PCR permitted to analyze the vectors collected in all sites. To determine $W$. bancrofti and P. falciparum infection by conventional PCR, DNA amplification was carried out following the procedure described by Farid et al., [28] and Morassin et al., [29] respectively. During analyze, the primers for the LAMP PCR have been received and used for the $W$. bancrofti gene detection from Sap$\tan$ mosquitoes which presented a diversity of species such as An. gambiae s.l., An. funestus s.l. and An. nili. This technique was performed according to the procedure described by Takagi et al., [30]. Then all positive pools for the LAMP PCR were systematically analyzed with the conventional PCR technique as described above just to confirm the results in accordance with those tested for the other five sites (Seiga, Koulpissy, Renghin, Tensobtenga and Tangonko).

\section{Data analysis}

Statistical analyses were performed using $\mathrm{R}$ software. The $\mathrm{R}$ commander package, version 4 Ri386, was used to perform the chi-square $\left(\chi^{2}\right)$ test with a probability threshold $p$-value $=5 \%$. The chi-square was used to compare the percentages of entomological parameters between species and collection period of the same site. The prevalence of $W$. bancrofti and P. falciparum infection in human was determined as the number of positive cases divided by total number tested. The chi-square test was used to compare both infections prevalence in human for each study site by collection period. The "Pool Screen ${ }^{\circledR} 2.0$ " software, using the algorithm of Katholi et al., [31] was used to calculate the parasite infection rates in vectors with $95 \%$ confidential interval.

\section{Ethical Approval}

Ethical approval was obtained from Institutional Ethics Committee of the Institut de Recherche en Sciences de la Santé and registered as $N^{\circ}$ A08/2014/ CEIRES. Written informed consent describing the potential risks and benefits of the study was obtained from all study participants before commencing the study and re-confirmed on each experimental night. Volunteers were screened for malaria and lymphatic filariasis parasites during recruitment. Those who were found malaria or lymphatic filariasis positive were offered treatment free of charge according to WHO recommendations. All Volunteers recruited received drug as a prophylactic measure during the study period to prevent disease. 


\section{Results}

\section{Prevalence of microfilariae and trophozoites in human populations}

A total of 1985 thick blood smears were analyzed, of which 652 were from August 2014 and 1333 were from September 2015 for all study sites. The results on LF prevalence are summarized in Table 2. The highest prevalence (upper 1\%) was recorded in Koulpissy, Renghin and Saptan in August 2014. In September 2015, the prevalence of LF significantly decreased compared to August 2014. Infection was only found in human populations in two sites namely Seiga and Tensobtenga (Table 2).

With regards the $P$. falciparum infection (Table 2), it was high in all sites with prevalence between 56.36\% and 81.43\% in August 2014. In September 2015, prevalence decreased in all sites, ranging between $24.89 \%$ and $54.07 \%$. Significant difference was observed in the prevalence of malaria in human populations between the two periods of collection $\left(p\right.$-value $\left.=2^{-6}\right)$.

For all human populations analyzed for LF and malaria co-infection, prevalence was $0.16 \%$ in August 2014 and $0.08 \%$ in September 2015 (Table 2). Only one co-infection case was found in each period of collection, precisely in Koulpissy (August 2014) and in Seiga (September 2015).

Table 2. Summary of lymphatic filariasis and malaria prevalence in human populations

\begin{tabular}{|c|c|c|c|c|c|c|c|}
\hline \multicolumn{8}{|c|}{ August 2014} \\
\hline Site & $\begin{array}{l}\text { Number } \\
\text { persons } \\
\text { examined }\end{array}$ & $\begin{array}{l}\text { LF cases } \\
\text { positives }\end{array}$ & $\begin{array}{c}\text { Malaria } \\
\text { cases } \\
\text { positives }\end{array}$ & $\begin{array}{l}\text { Co-infection } \\
\text { cases } \\
\text { positives }\end{array}$ & $\begin{array}{l}\text { Prevalence of } W \text {. } \\
\text { bancrofti infection } \\
\text { (\%) }\end{array}$ & $\begin{array}{l}\text { Prevalence of } P \text {. } \\
\text { falciparum infection } \\
(\%)\end{array}$ & $\begin{array}{c}\text { Prevalence of both } \\
\text { parasites } \\
\text { co-infection (\%) }\end{array}$ \\
\hline Seiga & 140 & 1 & 114 & 0 & 0.71 & 81.43 & 0 \\
\hline Koulpissy & 106 & 3 & 74 & 1 & 2.83 & 69.81 & 0.94 \\
\hline Renghin & 81 & 1 & 68 & 0 & 1.23 & 83.95 & 0 \\
\hline Tangonko & 93 & 0 & 60 & 0 & 0 & 64.52 & 0 \\
\hline $\begin{array}{c}\text { Tensobteng } \\
\mathrm{a}\end{array}$ & 110 & 0 & 62 & 0 & 0 & 56.36 & 0 \\
\hline Saptan & 122 & 1 & 85 & 0 & 1.64 & 69.67 & 0 \\
\hline Total & 652 & 6 & 463 & 1 & 0.92 & 71.01 & 0.16 \\
\hline \multicolumn{8}{|c|}{ September 2015} \\
\hline Seiga & 296 & 1 & 75 & 1 & 0.34 & 25.34 & 0.34 \\
\hline Koulpissy & 282 & 0 & 82 & 0 & 0 & 29.08 & 0 \\
\hline Renghin & 226 & 0 & 76 & 0 & 0 & 33.63 & 0 \\
\hline Tangonko & 87 & 0 & 24 & 0 & 0 & 27.59 & 0 \\
\hline $\begin{array}{c}\text { Tensobteng } \\
\mathrm{a}\end{array}$ & 233 & 1 & 58 & 0 & 0.43 & 24.89 & 0 \\
\hline Saptan & 209 & 0 & 113 & 0 & 0 & 54.07 & 0 \\
\hline Total & 1333 & 2 & 428 & 1 & 0.15 & 32.11 & 0.08 \\
\hline
\end{tabular}

LF: Lymphatic filariasis. 


\section{Vector abundance and Anopheles species composition}

The Culicidae fauna collected by the two collection methods in all health districts was composed of different species (Table 3 and Table 4). A total of 29,183 mosquitoes were collected with 9098 in August 2014 and 20085 in September 2015 throughout the four health districts. The number of vectors was significantly different between the periods of collection $(p$-value $=0.000016)$. However, the number of mosquitoes caught by HLC indoor (11,924 mosquitoes) was not significantly higher than that recorded outdoor (10,243 mosquitoes) ( $p$-value

Table 3. Mosquito species composition collected by Hunam Landing Catches (HLC) method.

\begin{tabular}{|c|c|c|c|c|c|c|c|c|c|c|c|}
\hline \multirow{3}{*}{ Sites } & \multirow{3}{*}{$\begin{array}{l}\text { Collection } \\
\text { site }\end{array}$} & \multicolumn{8}{|c|}{ August 2014} & \multirow{3}{*}{\multicolumn{2}{|c|}{ Total }} \\
\hline & & \multicolumn{4}{|c|}{ Anophelinae } & \multicolumn{4}{|c|}{ Culicinae } & & \\
\hline & & $\begin{array}{c}\text { An. } \\
\text { gambiae } \\
\text { s.l. }\end{array}$ & $\begin{array}{c}\text { An. } \\
\text { funestus } \\
\text { s.l. }\end{array}$ & An. nili & $\begin{array}{c}\text { An. } \\
\text { pharoensis }\end{array}$ & $\begin{array}{c}\text { Other } \\
\text { Anopheles }\end{array}$ & Aedes s.p. & Culex s.p. & $\begin{array}{c}\text { Mansonia } \\
\text { s.p. }\end{array}$ & & \\
\hline \multirow[t]{2}{*}{ Seiga } & Indoor & 634 & 1 & 0 & 1 & 0 & 7 & 1 & 1 & 645 & \multirow{2}{*}{1155} \\
\hline & Outdoor & 494 & 0 & 0 & 0 & 0 & 15 & 1 & 0 & 510 & \\
\hline \multirow[t]{2}{*}{ Koulpissy } & Indoor & 639 & 0 & 0 & 0 & 0 & 5 & 0 & 7 & 651 & \multirow{2}{*}{1325} \\
\hline & Outdoor & 658 & 0 & 0 & 0 & 0 & 12 & 0 & 4 & 674 & \\
\hline \multirow[t]{2}{*}{ Renghin } & Indoor & 496 & 0 & 0 & 0 & 0 & 1 & 30 & 0 & 527 & \multirow{2}{*}{959} \\
\hline & Outdoor & 369 & 4 & 0 & 3 & 1 & 13 & 38 & 4 & 432 & \\
\hline \multirow[t]{2}{*}{ Tensobtenga } & Indoor & 633 & 0 & 0 & 0 & 0 & 1 & 0 & 1 & 635 & \multirow{2}{*}{1352} \\
\hline & Outdoor & 699 & 0 & 0 & 0 & 0 & 7 & 8 & 3 & 717 & \\
\hline \multirow[t]{2}{*}{ Tangonko } & Indoor & 517 & 0 & 0 & 0 & 0 & 2 & 66 & 0 & 585 & \multirow{2}{*}{1198} \\
\hline & Outdoor & 504 & 0 & 0 & 0 & 0 & 7 & 102 & 0 & 613 & \\
\hline \multirow[t]{2}{*}{ Saptan } & Indoor & 198 & 206 & 120 & 0 & 4 & 19 & 2 & 48 & 597 & \multirow{2}{*}{1038} \\
\hline & Outdoor & 143 & 74 & 127 & 0 & 9 & 45 & 0 & 43 & 441 & \\
\hline \multicolumn{12}{|c|}{ September 2015} \\
\hline Seiga & Indoor & 2500 & 0 & 0 & 0 & 0 & 9 & 2 & 0 & 2511 & \multirow{2}{*}{4832} \\
\hline & Outdoor & 2292 & 0 & 0 & 0 & 0 & 26 & 3 & 0 & 2321 & \\
\hline \multirow[t]{2}{*}{ Koulpissy } & Indoor & 1286 & 0 & 0 & 0 & 0 & 7 & 0 & 0 & 1293 & \multirow{2}{*}{2310} \\
\hline & Outdoor & 997 & 0 & 0 & 0 & 0 & 15 & 0 & 5 & 1017 & \\
\hline \multirow[t]{2}{*}{ Renghin } & Indoor & 2058 & 0 & 0 & 0 & 0 & 7 & 13 & 0 & 2078 & \multirow{2}{*}{3546} \\
\hline & Outdoor & 1441 & 0 & 0 & 4 & 0 & 11 & 12 & 0 & 1468 & \\
\hline \multirow[t]{2}{*}{ Tensobtenga } & Indoor & 1021 & 0 & 0 & 0 & 0 & 3 & 5 & 2 & 1031 & \multirow{2}{*}{1602} \\
\hline & Outdoor & 549 & 0 & 0 & 1 & 0 & 4 & 5 & 12 & 571 & \\
\hline \multirow[t]{2}{*}{ Tangonko } & Indoor & 445 & 0 & 0 & 1 & 1 & 4 & 92 & 0 & 543 & \multirow{2}{*}{1005} \\
\hline & Outdoor & 382 & 1 & 0 & 0 & 2 & 9 & 65 & 3 & 462 & \\
\hline \multirow[t]{2}{*}{ Saptan } & Indoor & 214 & 22 & 570 & 1 & 8 & 3 & 7 & 3 & 828 & \\
\hline & Outdoor & 105 & 8 & 851 & 0 & 16 & 1 & 26 & 10 & 1017 & 1045 \\
\hline
\end{tabular}


Table 4. Mosquito species composition and physiological status of An. gambiae s.l. and An. funestus s.l. collected by pyrethrum spray catches (PSC) method in the study sites.

\begin{tabular}{|c|c|c|c|c|c|c|c|c|c|c|c|c|c|}
\hline \multicolumn{14}{|c|}{ August 2014} \\
\hline \multirow{3}{*}{ Sites } & \multicolumn{10}{|c|}{ Anophelinae } & \multicolumn{2}{|c|}{ Culicinae } & \multirow{3}{*}{ Total } \\
\hline & \multicolumn{4}{|c|}{ An. gambiae s.I. } & \multicolumn{4}{|c|}{ An. funestus s.l. } & \multirow{2}{*}{ An. nili } & \multirow{2}{*}{ Other Anopheles } & \multirow{2}{*}{ Culex s.p. } & \multirow{2}{*}{ Aedes s.p. } & \\
\hline & Unfed & Fed & Half-gravid & Gravid & Unfed & Fed & Half-gravid & Gravid & & & & & \\
\hline Seiga & 7 & 159 & 0 & 49 & 0 & 0 & 0 & 0 & 0 & 0 & 14 & 1 & 230 \\
\hline Koulpissy & 48 & 617 & 5 & 159 & 0 & 0 & 0 & 0 & 0 & 0 & 40 & 1 & 870 \\
\hline Renghin & 21 & 157 & 5 & 103 & 0 & 0 & 0 & 0 & 0 & 0 & 49 & 1 & 336 \\
\hline Tensobtenga & 12 & 132 & 3 & 28 & 0 & 0 & 0 & 0 & 0 & 0 & 40 & 0 & 215 \\
\hline Tangonko & 12 & 206 & 0 & 104 & 0 & 1 & 0 & 0 & 0 & 2 & 156 & 0 & 481 \\
\hline Saptan & 6 & 58 & 1 & 4 & 2 & 32 & 3 & 7 & 0 & 0 & 0 & 0 & 113 \\
\hline Total & 106 & 1329 & 14 & 447 & 2 & 33 & 3 & 7 & 0 & 2 & 299 & 3 & 2245 \\
\hline \multicolumn{14}{|c|}{ September 2015} \\
\hline Seiga & 218 & 816 & 49 & 260 & 0 & 0 & 0 & 0 & 0 & 5 & 441 & 2 & 1791 \\
\hline Koulpissy & 107 & 687 & 79 & 170 & 0 & 0 & 0 & 0 & 0 & 0 & 10 & 0 & 1053 \\
\hline Renghin & 233 & 845 & 71 & 233 & 0 & 0 & 0 & 0 & 0 & 0 & 76 & 0 & 1458 \\
\hline Tensobtenga & 36 & 249 & 24 & 44 & 0 & 0 & 0 & 0 & 0 & 0 & 43 & 0 & 396 \\
\hline Tangonko & 12 & 64 & 5 & 29 & 0 & 0 & 0 & 0 & 0 & 0 & 126 & 0 & 236 \\
\hline Saptan & 3 & 55 & 3 & 1 & 0 & 0 & 0 & 1 & 2 & 0 & 3 & 1 & 69 \\
\hline Total & 609 & 2716 & 231 & 737 & 0 & 0 & 0 & 1 & 2 & 5 & 699 & 3 & 5003 \\
\hline
\end{tabular}

$=0.062)$. Anopheles gambiae s.l. was predominant in both collection periods (87.25\%) in all sites followed by An. nili (5.72\%) and An. funestus s.l. (1.24\%) in Saptan. Aedes s.p. (0.82\%), Culex s.p. (5.06\%) and Mansonia s.p. (0.005\%) were found in relatively low proportions (Table 3 and Table 4).

\section{Anopheles gambiae sensu lato sibling species distribution}

Overall, 360 An. gambiae s.l. ( $\mathrm{n}=30$ per site) were analyzed to identify the sibling species encountered in the study sites. In August 2014, An. coluzzii was found predominant in Koulpissy (86.7\%) and Renghin (76.7\%). However, An. gambiae represented more than $60 \%$ of the complex species in Seiga, Tangonko, Tensobtenga and Saptan. In September 2015, An. coluzzii was the most encountered in all the sites except in Saptan and Tangonko where An. gambiae was predominant with more than $50 \%$ (Figure 2). An. arabiensis was observed in low frequencies in all the sites regardless the collection period.

\section{Vector biting and resting behaviors}

The variations in the feeding behaviors of An. gambiae s.l., An. funestus s.l., and An. nili in both collection periods are shown in Figure 3. Overall, in all sites, An. gambiae s.l. exhibited endophagic behavior in August 2014 as well as in September 2015 ( $p$-value $=0.05$ ). Indeed, 50\% to $70 \%$ of this species were collected indoor regardless the site and the period. In Saptan, An. funestus s.l. was 


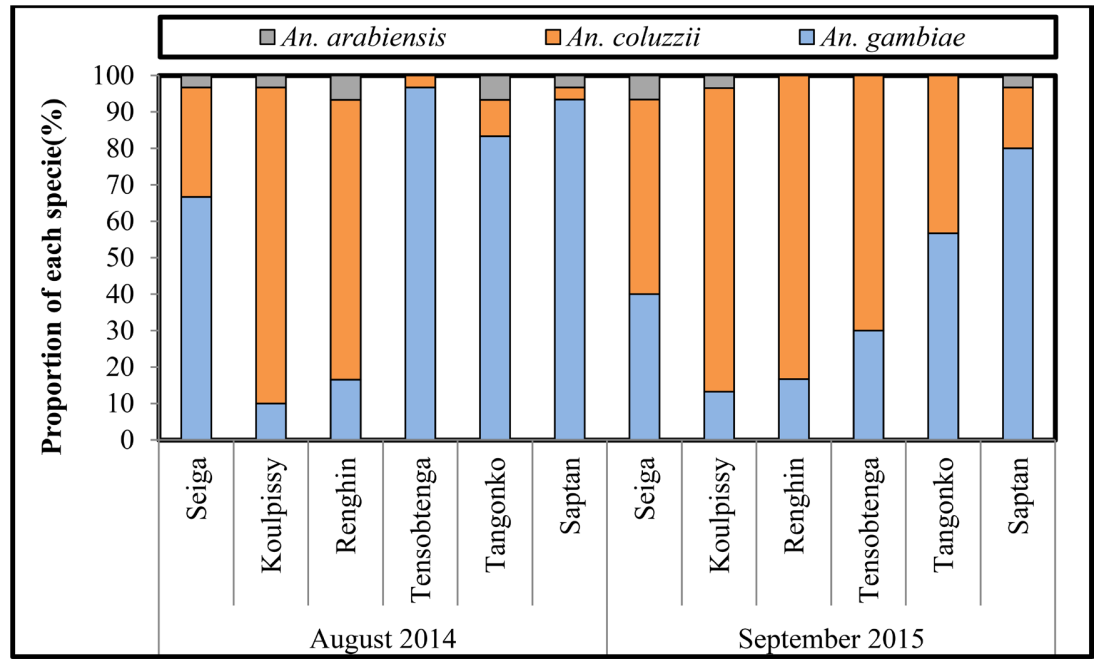

Figure 2. Anopheles gambiae s.l. sibling species composition following the study sites.

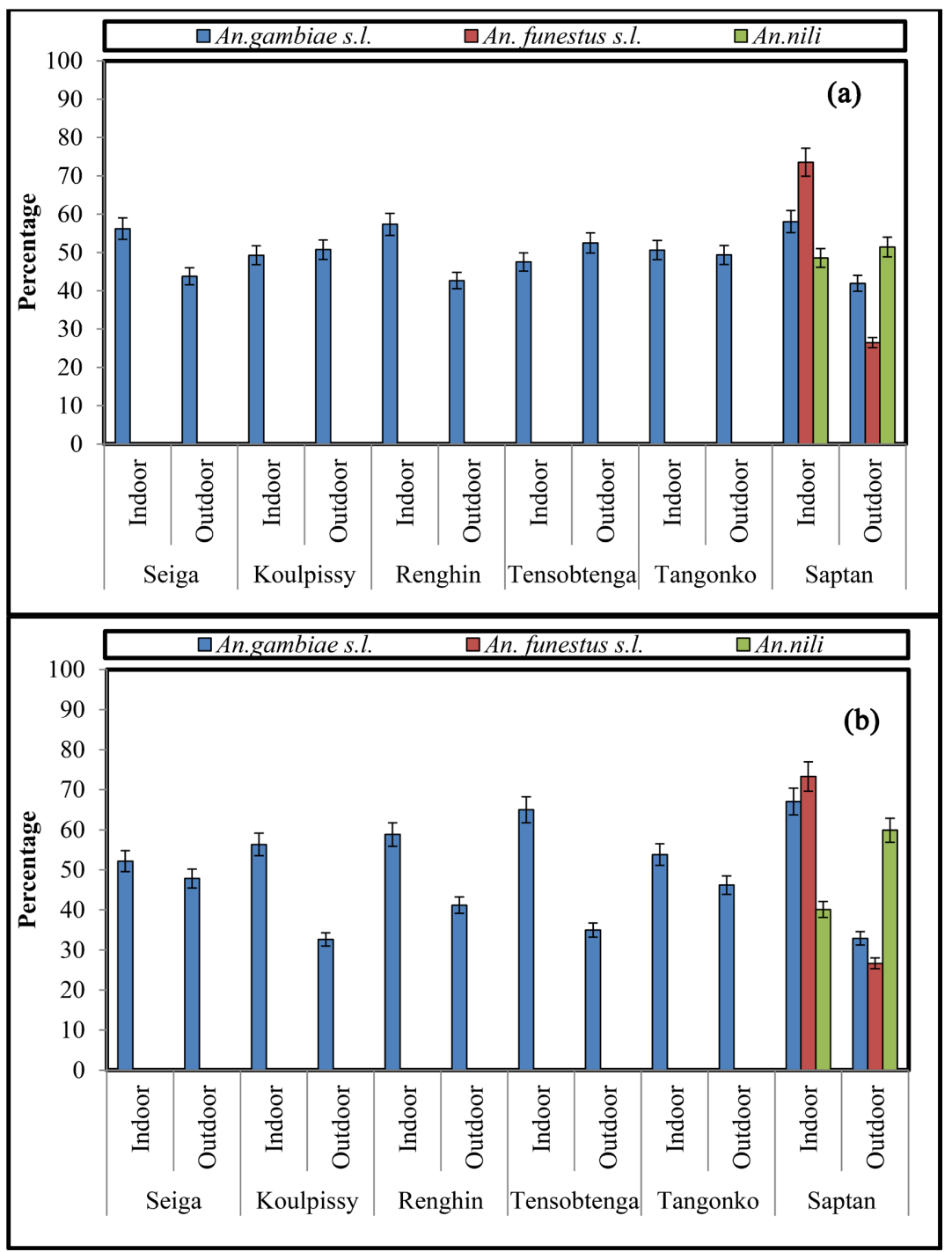

Figure 3. Feeding behaviors of Anopheles species in the study sites, (a) August 2014 and (b) September 2015. 
also found endophagic regardless the site and the period. Anopheles nili, showed exophagic as well as endophagic behaviors in Saptan in August 2014 (Figure 3(a)) but exhibited an exophagic trend in September 2015 (Figure 3(b)).

The residual fauna collected by PSC showed that An. gambiae s.l. were relatively the main vector in all sites except in Saptan where few females of $A n$. funestus s.l. were collected in August 2014 (Figure 4). These vectors exhibited an endophily behavior with high number of specimens resting indoor. No An. nili was collected in both collection periods. Therefore, this vector is potentially exophilic. More mosquitoes were collected in September 2015 than in August 2014 regardless the site $(p$-value $<0.05)$.

\section{Parity rate of Anopheles gambiae sensu lato}

Figure 5 shows the parity rates in all sites in both collection periods. In Seiga, Koulpissy, Renghin, Tensobtenga and Tangonko, females caught indoor as well as outdoor in August 2014 were majorly parous (which had already laid eggs at least once) (Figure 5(a)). In these sites, the mean parity rate was $68.44 \%$ (CI: 56.4 - 86.52) for An. gambiae s.l. However, in Saptan, more parous An. gambiae s.l. females were caught indoor (parity rate $80 \%$; CI: 75.22-84.30) than outdoor (46.67\%; CI: 40.2 - 52.30) (Figure 5(a)). In September 2015, the vectors sampled in Seiga, Tensobtenga and Tangonko were in majority parous in indoors as well as outdoors (Figure 5(b)). During this same collection period, the parity rates of vectors collected in Koulpissy and Renghin have decreased compared to August 2014. However, in Koulpissy the parity rate was higher indoor than outdoor. In Saptan, females collected indoor as well as outdoor were majorly parous (Figure 5(b)), but the parity rate was higher outdoor than indoor. The parity rates were not different between indoor and outdoor in all sites by collection period $(p$-value $=0.1027)$. However, a significant different was noted in parity rates

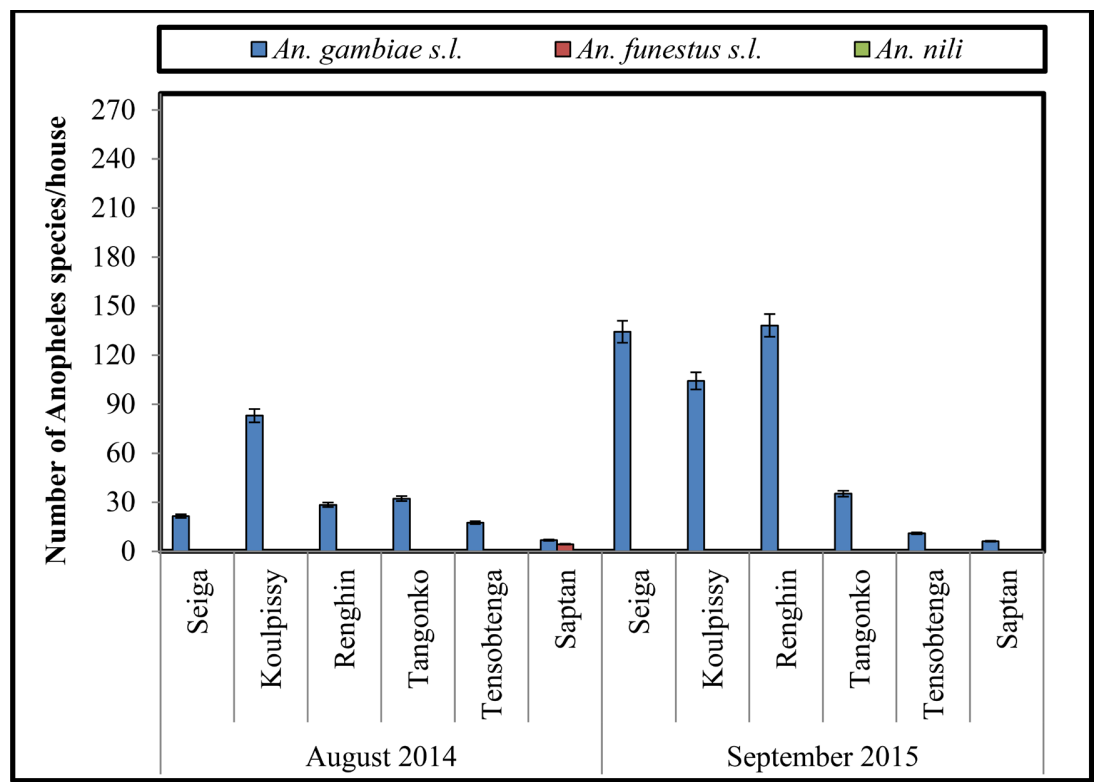

Figure 4. Mean number of mosquitoes collected by Pyrethrum Spray Catch (PSC) throughout the study sites. 


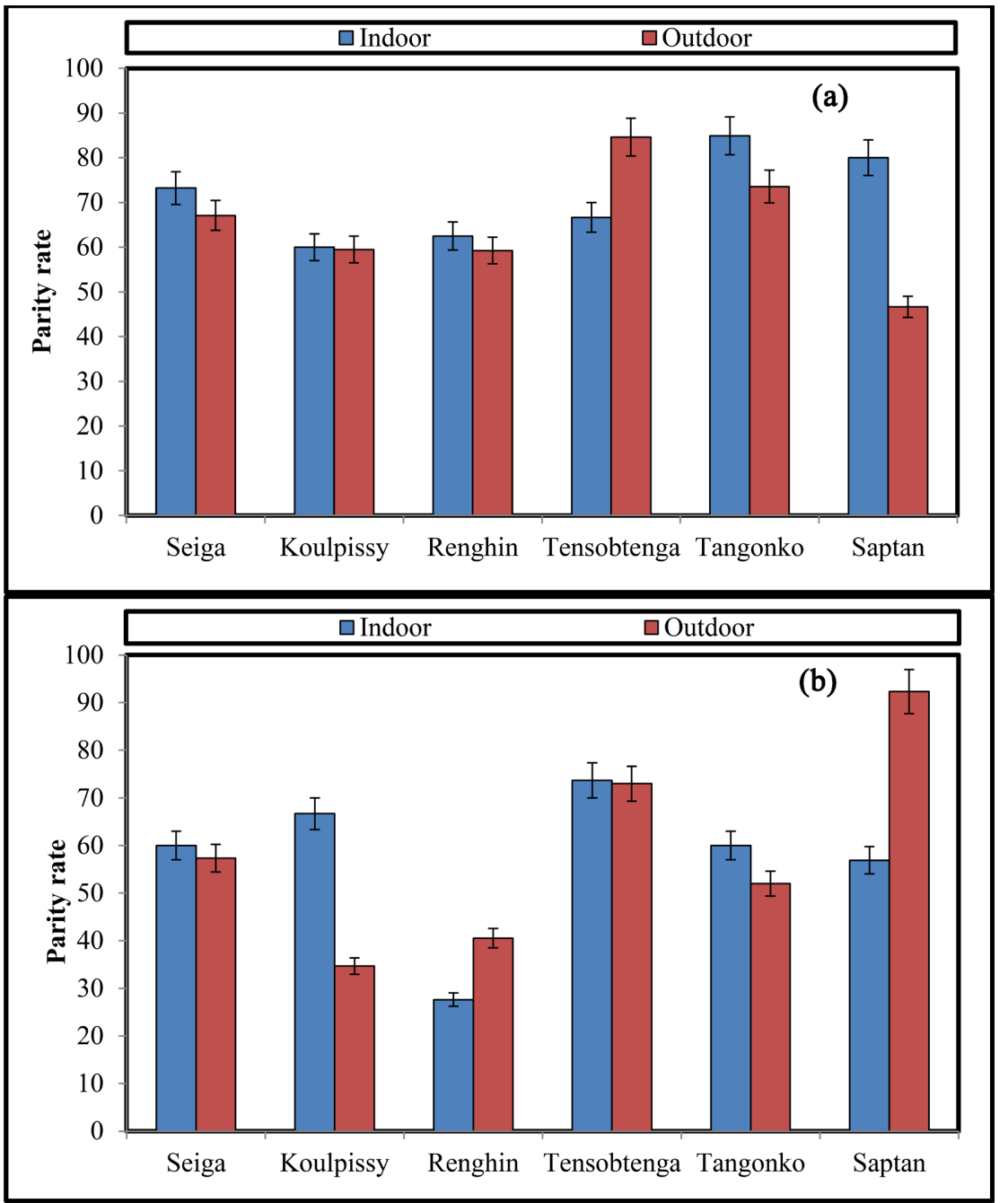

Figure 5. Parity rates of Anopheles gambiae s.l. collected in the study sites, August 2014 (a) and September 2015 (b).

between collection period ( $p$-value $<0.05)$.

Blood meal source of Anopheles gambiae sensu lato collected by Pyrethrum Spray Catch

In all the sites, An. gambiae s.l. vectors showed anthropophagic behavior except in Koulpissy and in Tangonko where mixed human and animal blood meal was found in high proportion up to 80\% in August 2014 (Figure 6). In September 2015, low proportion and or no mixed blood meal was found in An. gambiae s.l.

Prevalence of Wuchereria bancrofti and Plasmodium falciparum infection in Anopheles populations

Table 5 shows the prevalence of $W$. bancrofti and P. falciparum in An. gambiae s.l. populations in Seiga, Koulpissy, Renghin, Tensobtenga and Tangonko in both collection periods. Wuchereria bancrofti infection was found only in Koulpissy (Fada health district) in August 2014 with an infection rate of 4.5\% (CI: [1.17 - 11.4]) and in Tensobtenga (Ouargaye health district) in September 2015 


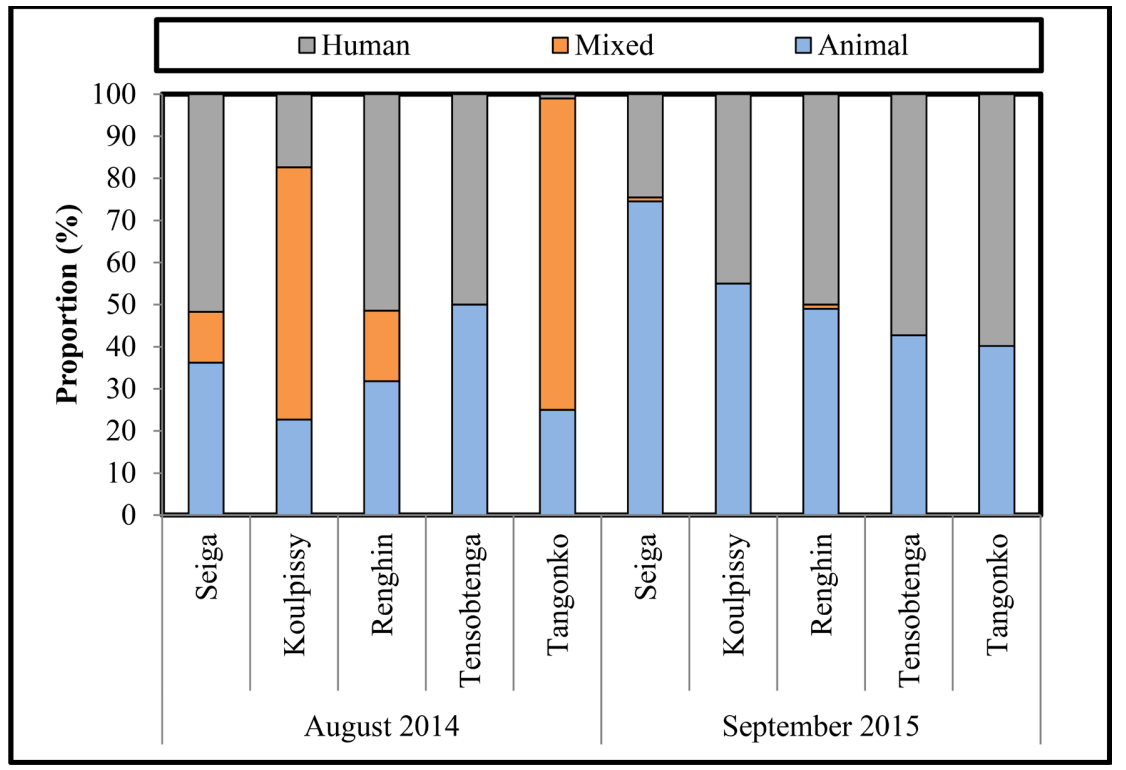

Figure 6. Anopheles gambiae s.l. blood meal source of in the study sites.

Table 5. Infections rates of Wucherira bancrofti and Plasmodium falciparum of An. gambiae s.l. populations from Seiga, Koulpissy, Renghin, Tensobtenga and Tangonko assessed by conventional PCR.

\begin{tabular}{|c|c|c|c|c|c|c|c|}
\hline \multirow[b]{2}{*}{ Site } & \multicolumn{7}{|c|}{ Anopheles gambiae s.l. } \\
\hline & $\begin{array}{c}\text { Date of } \\
\text { collection }\end{array}$ & $\begin{array}{c}\mathrm{Nb} \text { pools } \\
\text { tested }\end{array}$ & $\begin{array}{c}\mathrm{Nb} \text { mosquitoes } \\
\text { tested }\end{array}$ & $\begin{array}{l}\text { Nb positive } \\
\text { pool } \\
W . \text { bancrofti }\end{array}$ & $\begin{array}{c}W . \text { bancrofti } \\
\text { infection } \\
\text { rates } \%[\mathrm{CI}]\end{array}$ & $\begin{array}{c}\mathrm{Nb} \text { positive } \\
\text { pool } \\
P . \text { falciparum }\end{array}$ & $\begin{array}{c}P . \text { falciparum } \\
\text { infection } \\
\text { rates } \%[\mathrm{CI}]\end{array}$ \\
\hline \multirow{2}{*}{ Seiga } & Aug 2014 & 13 & 100 & 0 & 0 & 2 & $2.1[0.2-7.3]$ \\
\hline & Sept-2015 & 10 & 100 & 0 & 0 & 0 & 0 \\
\hline \multirow{2}{*}{ Koulpissy } & Aug 2014 & 15 & 100 & 4 & $4.5[1.17-11.4]$ & 4 & $4.5[1.17-11.4]$ \\
\hline & Sept-2015 & 10 & 100 & 0 & 0 & 2 & $2[2.2-7.54]$ \\
\hline \multirow{2}{*}{ Renghin } & Aug 2014 & 14 & 100 & 0 & 0 & 2 & $2.1[0.2-7.3]$ \\
\hline & Sept-2015 & 10 & 100 & 0 & 0 & 1 & $1.04[0.03-5.2]$ \\
\hline \multirow{2}{*}{ Tensobtenga } & Aug 2014 & 13 & 100 & 0 & 0 & 5 & $6.5[1.9-15]$ \\
\hline & Sept-2015 & 10 & 100 & 1 & $1.04[0.03-5.2]$ & 1 & $1.04[0.03-5.2]$ \\
\hline \multirow{2}{*}{ Tangonko } & Aug 2014 & 13 & 100 & 0 & 0 & 1 & $1[0.03-5.2]$ \\
\hline & Sept-2015 & 10 & 100 & 0 & 0 & 1 & $1.04[0.03-5.2]$ \\
\hline
\end{tabular}

$\mathrm{Nb}$ : Number.

with infection rate of $1.04 \%$ (CI: [0.03 - 5.2]). Plasmodium falciparum infection was found in all the sites in both collection periods, except in Seiga in September 2015. The highest infection rates of $P$. falciparum were observed in Tensobtenga (6.5\%, CI: [1.9 - 15]) and Koulpissy (4.5\%, CI: [1.17 - 11.4]) in August 2014. The prevalence of $P$. falciparum decreased in September 2015 compared to August 2014.

In addition, the pools of Saptan constituted by An. gambiale s.l., An. funestus s.l. and An. nili sampled both in August 2014 and in September 2015 were tested 
first using LAMP technique and secondly with conventional PCR for $W$. bancrofti detection. The results of LAMP technique showed that both An. funestus s.l. and An. nili were infected by W. bancrofti respectively in August 2014 and September 2015 with related infection rates of $0.5 \%$ [0.05 - 2.9] and 0.06\% [0.002 - 0.3] respectively (Table 6). Therefore, these results were checked by conventional PCR that confirmed only An. nili as effectively positive to W. bancrofti reaching an infection rate of $0.8 \%$ [0.3 - 1.4] in September 2015. The pool positive of An. funestus s.l. failed to be confirmed by conventional PCR. No An. gambiae s.l. pool was tested positive to $W$. bancrofti neither by LAMP PCR none by conventional PCRs in Saptan. However, in Saptan, the infection status of $P$. falciparum was confirmed only by conventional PCR within An. gambiale s.l., An. funestus s.l. and An. nili populations. The results showed that An. gambiae s.l. was higher infected with infection rates of $0.9 \%$ (CI: [0.02 - 4]) and 2\% (CI: [0.38 - 5.7]) in August 2014 and September 2015 respectively (Table 6). Only one pool of An. nili confirmed by conventional PCR as effectively positive to $P$. falciparum reaching an infection rate of 0.8\% (CI: [0.3 - 1.4]) in September 2015. No An. funestus s.l. pool was tested positive to $P$. falciparum by conventional PCRs in Saptan.

A co-infection of W. bancrofti / P. falciparum was found within An. gambiae s.l. populations in Koulpissy (Fada health district) in August 2014 with an infection rate of $2.25 \%$ (CI: [0.58 - 5.7]) and in Tensobtenga with an infection rate of 1.04\% (CI: [0.03 - 5.2]) in September 2015 (Table 7). In Saptan, only An. nili was found to be co-infected with an infection rate of $0.8 \%$ (CI: [0.3 - 1.4]).

Anopheles gambiae s.l. sibling species identification revealed that all positive

Table 6. Infections rates of Wuchereria bancrofti and Plasmodium falciparum of An. gambiae s.l., An. funestus s.l. and An. nili by populations compared between LAMP and conventional PCR at Saptan in the Diébougou health district.

\begin{tabular}{|c|c|c|c|c|c|c|c|c|c|c|c|c|}
\hline \multirow[b]{2}{*}{ Type of PCR } & \multicolumn{6}{|c|}{ August 2014} & \multicolumn{6}{|c|}{ September 2015} \\
\hline & 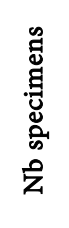 & 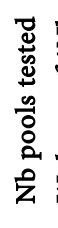 & 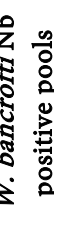 & 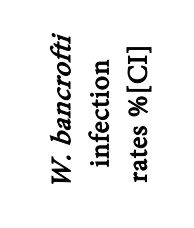 & 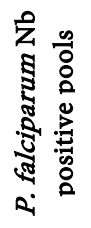 & 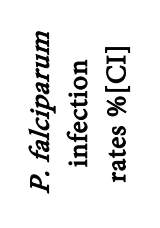 & 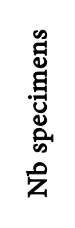 & 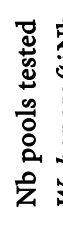 & 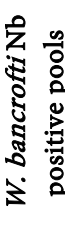 & 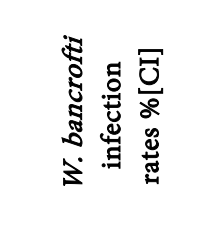 & 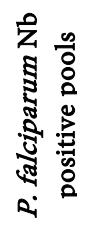 & 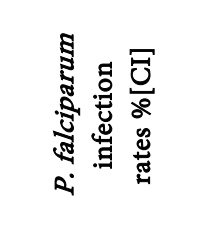 \\
\hline \multicolumn{13}{|c|}{ An. funestus } \\
\hline LAMP PCR & 385 & 6 & 1 & $0.5[0.05-2.9]$ & - & - & 33 & 2 & 0 & 0 & - & - \\
\hline Conventional PCR & 385 & 9 & 0 & 0 & 0 & 0 & 33 & 2 & 0 & 0 & 0 & 0 \\
\hline \multicolumn{13}{|c|}{ An. nili } \\
\hline LAMP PCR & 256 & 8 & 1 & $0.012[0.1-1.2]$ & - & - & 1423 & 65 & 10 & $0.71[0.3-1.4]$ & - & - \\
\hline Conventional PCR & 256 & 8 & 0 & 0 & 0 & 0 & 1423 & 65 & 1 & $0.06[0.002-0.3]$ & 1 & $0.06[0.002-0.3]$ \\
\hline \multicolumn{13}{|c|}{ An. gambiae s.l. } \\
\hline LAMP PCR & 186 & 6 & 0 & 0 & - & - & 206 & 9 & 0 & 0 & - & - \\
\hline Conventional PCR & 186 & 6 & 0 & 0 & 1 & $0.9[0.02-4]$ & 206 & 9 & 0 & 0 & 3 & $2[0.38-5.7]$ \\
\hline
\end{tabular}


Table 7. Co-infections rates of Wucherira bancrofti and Plasmodium falciparum of An. gambiae s.l. populations from the five study sites assessed by conventional PCR.

\begin{tabular}{|c|c|c|c|c|c|}
\hline \multirow[b]{2}{*}{ Site } & \multicolumn{5}{|c|}{ Anopheles gambiae s.l. } \\
\hline & Date of collection & $\begin{array}{l}\mathrm{Nb} \text { pools } \\
\text { tested }\end{array}$ & $\begin{array}{l}\mathrm{Nb} \text { mosquitoes } \\
\text { tested }\end{array}$ & $\begin{array}{c}\text { Nb positive pool } \\
W . \text { bancroftil } P \text {. falciparum }\end{array}$ & $\begin{array}{l}\text { Co-infection } \\
\text { rates } \%[\mathrm{CI}]\end{array}$ \\
\hline \multirow{2}{*}{ Seiga } & August 2014 & 13 & 100 & 0 & 0 \\
\hline & September 2015 & 10 & 100 & 0 & 0 \\
\hline \multirow{2}{*}{ Koulpissy } & August 2014 & 15 & 100 & 2 & $2.25[0.58-5.7]$ \\
\hline & September 2015 & 10 & 100 & 0 & 0 \\
\hline \multirow{2}{*}{ Renghin } & August 2014 & 14 & 100 & 0 & 0 \\
\hline & September 2015 & 10 & 100 & 0 & 0 \\
\hline \multirow{2}{*}{ Tensobtenga } & August 2014 & 13 & 100 & 0 & 0 \\
\hline & September 2015 & 10 & 100 & 1 & $1.04[0.03-5.2]$ \\
\hline \multirow{2}{*}{ Tangonko } & August 2014 & 13 & 100 & 0 & 0 \\
\hline & September 2015 & 10 & 100 & 0 & 0 \\
\hline
\end{tabular}

samples for $W$. bancrofti infection and $W$. bancroftil $P$. falciparum co-infection were An. coluzzii. However, the positive samples for $P$. falciparum were mainly composed of An. gambiae followed by An. coluzzii in all sites in both collection periods.

\section{Discussion}

Integrated management of LF and malaria in the hotspot health districts in Burkina Faso is poorly documented. To control LF and malaria, vector management integrated is currently implementing. However, to set up a better control strategy, it is important to obtain local information on the prevalence of these diseases, the vector diversity and behavior. The main objective of the present study was to collect baseline data towards developing and implementing an effective strategy integrating vector management to tackle both diseases simultaneously. It has investigated the (co-)transmission of malaria and LF and their vector behavior in endemic areas in Burkina Faso.

Malaria was found in almost all the sites while LF was recorded only two sites whiten the study periods in human populations. Malaria prevalence was higher than LF. A low co-infection rate with $W$. bancrofti and P. falciparum was noted. Our results are consistent with those of Kima et al., [9] and Gonçalves et al., [32] who reported $W$. bancrofti and P. falciparum infections in human populations in the same health districts. The Plasmodium falciparum infection rate decreased in September 2015 in all sites compared to August 2014. This may partly due according to the MDA with ivermectin/albendazol [33] [34] and the use of LLINs which reduces the human-vector contact [35].

Anopheles gambiae complex was the main vector collected by HLC and PSC in both collection periods in all health districts. This complex was mainly com- 
posed of An. coluzzii followed by An. gambiae and An. arabiensis. In Diébougou health district precisely in Saptan, An. funestus s.l. and An. nili was collected in high proportion in addition to An. gambiae s.l. These observations are consistent with previous studied which have reported the presence of the same vectors in the study areas [3] [21]. In addition, our results show that An. gambiae s.l., An. funestus s.l. and An. nili are sympatric in Saptan as reported by Soma et al., [36] in Diébougou health district.

Vector densities were higher in September 2015 compared to August 2014 and their distributions differ between sites. This variability may be explained by climate variations since our study sites are in different climatic regions. Indeed, it is known environmental conditions including rainfalls, vegetation, elevation, and anthropism affect the vector distribution [5] [37] [38]. The presence of three vector species (An. gambiae s.l., An. funestus s.l. and An. nili) in Diébougou health district (Saptan) in contrast to the other sites reveals favorable conditions for the development of these Anopheles species.

According to Manguin et al., [4] and Ashton et al., [35], W. bancrofti and P. falciparum transmission in a vector population depends on the ability of mosquitoes to ingest and support the development of parasites. Thus, the higher infection rates for $P$. falciparum than those of $W$. bancrofti observed in Anopheles species can be explained by the latent period of $W$. bancrofti in the vector which is usually long in relation to the vector life expectancy [4]. In contrast, the extrinsic cycle of malaria parasites lasts 9 - 10 days but can sometimes last for only five days [39]. Consequently, more filarial-infected mosquitoes than malaria-infected ones are likely to die before the parasites mature to the infective stage. A support for this is seen in the previous work in an endemic area along the Kenyan Coast where 17 mosquitoes harboured both $P$. falciparum sporozoites and immature stages of $W$. bancrofti while only two had sporozoites and infective larvae [40]. Anopheles coluzzii, An. gambiae and An. nili which were found to carry both parasite genes are considered as the potential vectors in the different study sites. Thus, persistence of LF and the malaria endemicity in the study sites may be correlated with the presence of An. gambiae, An. coluzzii and An. nili found in high proportion with old age vectors that are in majority parous females.

The Anopheles species sampled in our study were active during nighttime and fed indoors as well as outdoors. Also, most vectors were exclusively anthropophilic or zoophilic. These different behaviors of An. gambiae s.l., An. funestus s.l. and An. nili in W. bancrofti and P. falciparum transmission have been observed and described by several authors [5] [37] [41] [42] in West Africa. Since many mosquitoes were found biting and resting inside the houses, the indoor residual spraying and the use of LLINs could be effective to control the diseases in these study sites. However, suitable insecticide must be employed, knowing the development of resistance by An. gambiae s.l. and An. funestus s.l. to several classes of insecticides in these areas documented by several authors [36] [43]. 
Moreover, the control exophilic and exophagic population requires integrated vector control strategies including the environmental management and genetic approaches.

\section{Conclusion}

The present study has monitored the prevalence of LF and malaria co-infection in both human and vector populations in endemic areas of Burkina Faso. In addition, the vector feeding, and resting behaviors were investigated. Results indicate residual transmission of $W$. bancrofti and $P$. falciparum. However, low prevalence of co-infection in both mosquito and human populations was recorded. The main vectors found were An. coluzzii, An. gambiae and An. nili. This study has provided baseline information which will be useful to the development and implementation of a better integrated strategy to control both diseases.

\section{Acknowledgements}

The authors express their gratitude to health worker community for their assistance to this study. They warmly thank the inhabitants of the study sites for allowing the study to be carried out in their villages. The authors thank also LAMIVECT to have supported the publication fees.

\section{Authors' Contributions}

SC, SPS, and RKD planned the experiments. SC, SPS and ASH conducted the experiments. SC, SPS and ASH analyzed the data. SC, SPS wrote the manuscript with inputs from ASH, ASN, IS, BR, LK, CB, RWB, GAO and RKD. All authors read and approved the final manuscript.

\section{Funding}

This work was funded by the Liverpool School for Tropical Medicine and PACER (Programme d'Appui et de développement des Centres d'Excellence Régionaux) from the West African Economic and Monetary Union (UEMOA).

\section{Conflicts of Interest}

The authors declare no conflicts of interest regarding the publication of this paper.

\section{References}

[1] World Health Organization (2019) World Malaria Report 2019. Report No. 978-924-156572-1, World Health Organization, Geneva, 232 p. https://www.who.int/publications-detail-redirect/9789241565721

[2] Kamgno, J. and Djeunga, H.N. (2020) Progress towards Global Elimination of Lymphatic Filariasis. The Lancet Global Health, 8, e1108-e1109. https://doi.org/10.1016/S2214-109X(20)30323-5

[3] Tandina, F., Doumbo, O., Traoré, S.F., Parola, P. and Robert, V. (2018) Mosquitoes (Diptera: Culicidae) and Mosquito-Borne Diseases in Mali, West Africa. Parasites \& 
vectors, 11, Article No. 467. https://doi.org/10.1186/s13071-018-3045-8

[4] Manguin, S., Bangs, M.J., Pothikasikorn, J. and Chareonviriyaphap, T. (2010) Review on Global Co-Transmission of Human Plasmodium Species and Wuchereria bancrofti by Anopheles Mosquitoes. Infection, Genetics and Evolution, 10, 159-177. https://doi.org/10.1016/j.meegid.2009.11.014

[5] Stanton, M.C., Molyneux, D.H., Kyelem, D., Bougma, R.W., Koudou, B.G. and KellyHope, L.A. (2013) Baseline Drivers of Lymphatic Filariasis in Burkina Faso. Geospatial Health, 8, 159-173. https://doi.org/10.4081/gh.2013.63

[6] Stone, C.M., Lindsay, S.W. and Chitnis, N. (2014) How Effective Is Integrated Vector Management against Malaria and Lymphatic Filariasis Where the Diseases Are Transmitted by the Same Vector? Carabin, H., editor. PLoS Neglected Tropical Diseases, 8, Article ID: e3393. https://doi.org/10.1371/journal.pntd.0003393

[7] Bhatt, S., Weiss, D.J., Cameron, E., Bisanzio, D., Mappin, B., Dalrymple, U., et al. (2015) The Effect of Malaria Control on Plasmodium falciparum in Africa between 2000 and 2015. Nature, 526, 207-211. https://doi.org/10.1038/nature15535

[8] NTD Modelling Consortium Lymphatic Filariasis Group (2019) The Roadmap towards Elimination of Lymphatic Filariasis by 2030: Insights from Quantitative and Mathematical Modelling. Gates Open Research, 3, Article No. 1538. https://doi.org/10.12688/gatesopenres.13065.1

[9] Kima, A., Guiguemde, K.T., Meda, Z.C., Bougma, R., Serme, M., Bougouma, C., et al. (2019) Évaluation de l'impact du traitement médicamenteux de masse contre la filariose lymphatique dans 3 districts sanitaires et implication en santé publique: à propos de 12 sites de surveillance épidémiologique au Burkina Faso. Médecine et Santé Tropicales, 29, 55-60.

[10] Ouedraogo, A.N., Somda, E.B., Traoré, F., Ouédraogo, M.S., Tapsoba, G.P., Ouangre/ Ouédraogo, A., et al. (2016) Impact du traitement de masse de la filariose lymphatique par l'albendazole-ivermectine en zone de savane: Cas de la région de l'Est du Burkina. Health Sciences and Disease, 17, 16-21. https://hsd-fmsb.org/index.php/hsd/article/view/731

[11] Hien, A.S., Soma, D.D., Sawadogo, S.P., Poda, S.B., Namountougou, M., Ouédraogo, G.A., et al. (2020) Effect of Bendiocarb (Ficam ${ }^{\circledR} 80 \%$ WP) on Entomological Indices of Malaria Transmission by Indoor Residual Spraying in Burkina Faso, West Africa. Advances in Entomology, 8, 158-178. https://doi.org/10.4236/ae.2020.84012

[12] Sanou. A. (2020) The Ecology and Behaviour of Insecticide Resistant Malaria Vectors and Implications for Control in Burkina Faso. PhD Thesis, University of Glasgow, Glasgow.

[13] Some, A., Zongo, I., N'cho Tchiekoi, B., Soma, D.D., Zogo, B., Ouattara, M., et al. (2020) Epidemiology of Malaria in an Area with Pyrethroid-Resistant Vectors in SouthWestern Burkina Faso: A Pre-Intervention Study. medRxiv. Cold Spring Harbor Laboratory Press, Cold Spring Harbor.

[14] Bockarie, M.J., Pedersen, E.M., White, G.B. and Michael, E. (2009) Role of Vector Control in the Global Program to Eliminate Lymphatic Filariasis. Annual Review of Entomology, 54, 469-487. https://doi.org/10.1146/annurev.ento.54.110807.090626

[15] van den Berg, H., Kelly-Hope, L.A. and Lindsay, S.W. (2013) Malaria and Lymphatic Filariasis: The Case for Integrated Vector Management. The Lancet Infectious Diseases, 13, 89-94. https://doi.org/10.1016/S1473-3099(12)70148-2

[16] Bockarie, M.J., Tavul, L., Kastens, W., Michael, E. and Kazura, J.W. (2002) Impact of Untreated Bednets on Prevalence of Wuchereria bancrofti Transmitted by Ano- 
pheles farauti in Papua New Guinea. Medical and Veterinary Entomology, 16, 116119. https://doi.org/10.1046/j.0269-283x.2002.00352.x

[17] Burkot, T.R., Garner, P., Paru, R., Dagoro, H., Barnes, A., McDougall, S., et al. (1990) Effects of Untreated Bed Nets on the Transmission of Plasmodium falciparum, P. vivax and Wuchereria bancrofti in Papua New Guinea. Transactions of the Royal Society of Tropical Medicine and Hygiene, 84, 773-739.

https://doi.org/10.1016/0035-9203(90)90073-N

[18] Webber, R.H. (1979) Eradication of Wuchereria bancrofti Infection through Vector Control. Transactions of the Royal Society of Tropical Medicine and Hygiene, 73, 722-724. https://doi.org/10.1016/0035-9203(79)90031-2

[19] Moiroux, N., Gomez, M.B., Pennetier, C., Elanga, E., Djènontin, A., Chandre, F., et al. (2012) Changes in Anopheles funestus Biting Behavior Following Universal Coverage of Long-Lasting Insecticidal Nets in Benin. The Journal of Infectious Diseases, 206, 1622-1629. https://doi.org/10.1093/infdis/jis565

[20] Riehle, M.M., Guelbeogo, W.M., Gneme, A., Eiglmeier, K., Holm, I., Bischoff, E., et al. (2011) A Cryptic Subgroup of Anopheles gambiae Is Highly Susceptible to $\mathrm{Hu}$ man Malaria Parasites. Science, 331, 596-598.

https://doi.org/10.1126/science.1196759

[21] Dabiré, K.R., Baldet, T., Diabaté, A., Dia, I., Costantini, C., Cohuet, A., et al. (2007) Anopheles funestus (Diptera: Culicidae) in a Humid Savannah Area of Western Burkina Faso: Bionomics, Insecticide Resistance Status, and Role in Malaria Transmission. Journal of Medical Entomology, 44, 990-997. https://doi.org/10.1093/jmedent/44.6.990

[22] Hien, A.S., Sangaré, I., Coulibaly, S., Namountougou, M., Paré-Toé, L, Ouédraogo, A.G., et al. (2017) Parasitological Indices of Malaria Transmission in Children under Fifteen Years in Two Ecoepidemiological Zones in Southwestern Burkina Faso. Journal of Tropical Medicine, 2017, Article ID: 1507829.

https://doi.org/10.1155/2017/1507829 https://www.ncbi.nlm.nih.gov/pmc/articles/PMC5327772/

[23] Murray, G.P., Lissenden, N., Jones, J., Voloshin, V., Toé, K.H., Sherrard-Smith, E., et al. (2020) Barrier Bednets Target Malaria Vectors and Expand the Range of Usable Insecticides. Nature Microbiology, 5, 40-47. https://doi.org/10.1038/s41564-019-0607-2

[24] Gillies, M.T. and Coetzee, M. (1987) A Supplement to the Anophelinae of Africa South of the Sahara. South African Institute for Medical Research, Johannesburg, Publication No. 55, 1-143.

[25] Detinova, T.S. (1962) Age-Grouping Methods in Diptera of Medical Importance with Special Reference to Some Vectors of Malaria. World Health Organization, Geneva.

[26] Beier, J.C., Perkins, P.V., Wirtz, R.A., Koros, J., Diggs, D., Gargan, T.P., et al. (1988) Bloodmeal Identification by Direct Enzyme-Linked Immunosorbent Assay (Elisa), Tested on Anopheles (Diptera: Culicidae) in Kenya. Journal of Medical Entomology, 25, 9-16. https://doi.org/10.1093/jmedent/25.1.9

[27] Santolamazza, F., Mancini, E., Simard, F., Qi, Y., Tu, Z. and della Torre, A. (2008) Insertion Polymorphisms of SINE200 Retrotransposons within Speciation Islands of Anopheles gambiae Molecular forms. Malaria Journal, 7, Article No. 163. https://doi.org/10.1186/1475-2875-7-163

[28] Farid, H.A., Hammad, R.E., Hassan, M.M., Morsy, Z.S., Kamal, I.H., Weil, G.J., et al. (2001) Detection of Wuchereria bancrofti in Mosquitoes by the Polymerase Chain 
Reaction: A Potentially Useful Tool for Large-Scale Control Programmes. Transactions of the Royal Society of Tropical Medicine and Hygiene, 95, 29-32. https://doi.org/10.1016/S0035-9203(01)90322-0

[29] Morassin, B., Fabre, R., Berry, A. and Magnaval, J.F. (2002) One Year's Experience with the Polymerase Chain Reaction as a Routine Method for the Diagnosis of Imported Malaria. The American Journal of Tropical Medicine and Hygiene, 66, 503 508.

[30] Takagi, H., Itoh, M., Kasai, S., Yahathugoda, T.C., Weerasooriya, M.V. and Kimura, E. (2011) Development of Loop-Mediated Isothermal Amplification Method for Detecting Wuchereria bancrofti DNA in Human Blood and Vector Mosquitoes. Parasitology International, 60, 493-497. https://doi.org/10.1016/j.parint.2011.08.018

[31] Katholi, C.R., Toé, L., Merriweather, A. and Unnasch, T.R. (1995) Determining the Prevalence of Onchocerca volvulus Infection in Vector Populations by Polymerase Chain Reaction Screening of Pools of Black Flies. The Journal of Infectious Diseases, 172, 1414-1417. https://doi.org/10.1093/infdis/172.5.1414

[32] Gonçalves, B.P., Kapulu, M.C., Sawa, P., Guelbéogo, W.M., Tiono, A.B., Grignard, L., et al. (2017) Examining the Human Infectious Reservoir for Plasmodium Falciparum Malaria in Areas of Differing Transmission Intensity. Nature Communications, 8, Article No. 1133. https://doi.org/10.1038/s41467-017-01270-4

[33] Chaccour, C., Hammann, F. and Rabinovich, N.R. (2017) Ivermectin to Reduce Malaria Transmission I. Pharmacokinetic and Pharmacodynamic Considerations Regarding Efficacy and Safety. Malaria Journal, 16, Article No. 161. https://doi.org/10.1186/s12936-017-1801-4

[34] Kobylinski, K.C., Sylla, M., Chapman, P.L., Sarr, M.D. and Foy, B.D. (2011) Ivermectin Mass Drug Administration to Humans Disrupts Malaria Parasite Transmission in Senegalese villages. American Journal of Tropical Medicine and Hygiene, 85, 3-5. https://doi.org/10.4269/ajtmh.2011.11-0160

[35] Ashton, R.A., Kyabayinze, D.J., Opio, T., Auma, A., Edwards, T., Matwale, G., et al. (2011) The Impact of Mass Drug Administration and Long-Lasting Insecticidal Net Distribution on Wuchereria bancrofti Infection in Humans and Mosquitoes: An Observational Study in Northern Uganda. Parasites \& Vectors, 4, Article No. 134. https://doi.org/10.1186/1756-3305-4-134

[36] Soma, D.D., Zogo, B.M., Somé, A., Tchiekoi, B.N., Hien, D.F.deS., Pooda, H.S., et al. (2020) Anopheles Bionomics, Insecticide Resistance and Malaria Transmission in Southwest Burkina Faso: A Pre-Intervention Study. PLoS ONE, 15, Article ID: e0236920. https://doi.org/10.1371/journal.pone.0236920

[37] de Souza, D.K., Koudou, B., Kelly-Hope, L.A., Wilson, M.D., Bockarie, M.J. and Boakye, D.A. (2012) Diversity and Transmission Competence in Lymphatic Filariasis Vectors in West Africa, and the Implications for Accelerated Elimination of Anopheles-Transmitted Filariasis. Parasites \& Vectors, 5, Article No. 259. https://doi.org/10.1186/1756-3305-5-259

[38] Koudou, B.G., de Souza, D.K., Biritwum, N.-K., Bougma, R., Aboulaye, M., Elhassan, E., et al. (2018) Elimination of Lymphatic Filariasis in West African Urban Areas: Is Implementation of Mass Drug Administration Necessary? The Lancet Infectious Diseases, 18, e214-e220. https://doi.org/10.1016/S1473-3099(18)30069-0

[39] Millen, D.B. (1986) A Strategy for Personal and Community Protection against the Vectors of Malaria in Papua New Guinea with Emphasis on the Evaluation of Bednets Impregnated with Permethrin. PhD Thesis, Department of Biological Sciences, Simon Fraser University, Burnaby.

[40] Muturi, E.J., Mbogo, C.M., Ng'ang'a, Z.W., Kabiru, E.W., Mwandawiro, C., Novak, 
R.J., et al. (2006) Relationship between Malaria and Filariasis Transmission Indices in an Endemic Area along the Kenyan Coast. Journal of Vector Borne Diseases, 43, 77-83.

[41] Ossè, R.A., Tokponnon, F., Padonou, G.G., Sidick, A., Aïkpon, R., Fassinou, A., et al. (2019) Involvement of Anopheles nili in Plasmodium falciparum Transmission in North Benin. Malaria Journal, 18, Article No. 152.

https://doi.org/10.1186/s12936-019-2792-0

[42] Pi-Bansa, S., Osei, J.H.N., Frempong, K.K., Elhassan, E., Akuoko, O.K., Agyemang, D., et al. (2019) Potential Factors Influencing Lymphatic Filariasis Transmission in "Hotspot" and "Control" Areas in Ghana: The Importance of Vectors. Infect Dis Poverty, 8, Article No. 9. https://www.ncbi.nlm.nih.gov/pmc/articles/PMC6362603/

[43] Briët, O.J.T., Penny, M.A., Hardy, D., Awolola, T.S., Van Bortel, W., Corbel, V., et al. (2013) Effects of Pyrethroid Resistance on the Cost Effectiveness of a Mass Distribution of Long-Lasting Insecticidal Nets: A Modelling Study. Malaria Journal, 12, Aticle No. 77. https://doi.org/10.1186/1475-2875-12-77 